\title{
Radiophotoluminescence Properties of Ag-Doped Phosphate Glasses Containing Different Alkali Metal Cations
}

\author{
Hironori Tanaka, ${ }^{*}$ Yutaka Fujimoto, Masanori Koshimizu, Takayuki Yanagida, ${ }^{1}$ \\ Takuma Yahaba, Keiichiro Saeki, and Keisuke Asai \\ Department of Applied Chemistry, Graduate School of Engineering, Tohoku University \\ 6-6-07 Aoba, Aramaki, Aoba-ku, Sendai, Miyagi 980-8579, Japan \\ ${ }^{1}$ Nara Institute of Science and Technology, 8916-5 Takayama, Ikoma, Nara 630-0192, Japan \\ (Received January 4, 2016; accepted May 18, 2016)
}

Keywords: radiophotoluminescence, dosimetry, phosphate glass

For many years, the radiophotoluminescence (RPL) of Ag-doped phosphate glass has been exploited in personal dosimetry. In this study, we investigated the optical properties of Ag-doped phosphate glasses of various compositions containing alkali metals as cations. We found that the peak wavelengths of the RPL bands depend on alkali metal species. Corresponding excitation bands also appeared in the excitation spectra after irradiation. In addition, we observed differences in the stability of the RPL fluorescent centers after heat treatment. These results indicate that RPL fluorescent center formation and initialization processes depend on the alkali metal species in the host phosphate glasses.

\section{Introduction}

Radiophotoluminescence (RPL) has been investigated for a long time in Ag-doped phosphate glasses (PGs) applied to passive dosimeters. In previous studies, the formation of fluorescent centers in Ag-doped phoshate glasses was investigated by Schulman and Compton, ${ }^{(1)}$ Yokota, ${ }^{(2,3)}$ and Miyamoto and co-workers ${ }^{(4,5)}$ by optical spectroscopy or electron spin resonance (ESR) measurements. The results indicate that the valence state of $\mathrm{Ag}^{+}$ions in the glasses changes upon exposure to X-ray, gamma ray, or intense laser irradiation. However, fluorescent center formation has not yet been conclusively elucidated. In addition to the fluorescent centers based on Ag, Okada et al. observed RPL in Sm-doped PGs after high-dose X-ray irradiation and ascribed the RPL to the valence change of $\mathrm{Sm}$ ions, i.e., $\mathrm{Sm}^{3+}$ to $\mathrm{Sm}^{2+}$.(6) Consequently, these glasses are applicable to medical and environmental dosimetry.

Although RPL is used in practical applications, some phenomena remain unexplained. For example, the 'build up' process, i.e., the gradual increase in fluorescence intensity over several tens of hours after irradiation, has not been throughly analyzed. Another example is the initialization of RPL by heating. Therefore, we began a detailed investigation on the factors affecting the RPL properties.

In this study, we focused on the composition of Ag-doped PGs. It has been reported that PGs containing over $40 \mathrm{~mol} \% \mathrm{NaPO}_{3}$ exhibit RPL, and that the $\mathrm{NaPO}_{3}$ content affects the RPL

"Corresponding author: e-mail: hironori.t@dc.tohoku.ac.jp 
fluorescence properties. ${ }^{(7)}$ In our previous research, we found that the presence of alkali metals in PG is necessary to achieve RPL, and the alkali metal content affects the RPL properties. ${ }^{(8)}$ In this study, we further investigated the effect of alkali metals in the host on the RPL properties. We investigated the photoluminescence (PL) and RPL properties of Ag-doped PGs, where the hosts are composed of alkali metal phosphates, i.e., $\mathrm{LiPO}_{3}, \mathrm{NaPO}_{3},\left(\mathrm{KPO}_{3}\right)_{n}, \mathrm{RbH}_{2} \mathrm{PO}_{4}$, and $\mathrm{CsH}_{2} \mathrm{PO}_{4}$. We investigated the correlation between the species of alkali metals and the RPL properties.

\section{Experiments}

All reagents were purchased from Kojundo Chemical Laboratory Co., Ltd. The glass samples were prepared by a conventional melt-quenching method in air. The raw materials, $\mathrm{AgCl}(99.99 \%)$ and $\mathrm{LiPO}_{3}(99 \%)$ (the prepared glass is called $\mathrm{Li} / \mathrm{Ag}$ hereafter), were mixed, loaded into an alumina crucible, and melted at $800-950{ }^{\circ} \mathrm{C}$ for $30 \mathrm{~min}$ in an electric furnace. Finally, the glass melt was quenched on a stainless-steel plate heated to $573 \mathrm{~K}$, a temperature below the glass-transition temperature of the PG. The same procedure was carried out with $\mathrm{NaPO}_{3}(99 \%)(\mathrm{Na} / \mathrm{Ag}),\left(\mathrm{KPO}_{3}\right)_{n}$ (99\%) $(\mathrm{K} / \mathrm{Ag}), \mathrm{RbH}_{2} \mathrm{PO}_{4}(99 \%)(\mathrm{Rb} / \mathrm{Ag})$, and $\mathrm{CsH}_{2} \mathrm{PO}_{4}(99 \%)(\mathrm{Cs} / \mathrm{Ag})$ in place of $\mathrm{LiPO}_{3}$. The $\mathrm{Ag}$ concentration was $0.1 \mathrm{~mol} \%$ for all PGs. The samples were irradiated at room temperature with X-rays using an X-ray tube operating at $40 \mathrm{~mA}$ and $40 \mathrm{kV}$. To ensure that the Ag fluorescent centers in the glass were stable after the irradiation, PL measurements were performed $24 \mathrm{~h}$ after irradiation. Furthermore, the PL spectra were measured after heat treatment to investigate the initialization process. The PL and RPL properties were analyzed using PL and RPL spectra and the temporal luminescence profiles. PL and RPL spectra were collected using an F-7000 (Hitachi) fluorescence spectrometer. The temporal profiles were recorded using DeltaFlex 3000U-TMK2 (Horiba). Absorption spectra were measured using a Hitachi U-3500 spectrophotometer.

\section{Results and Discussion}

\subsection{PL and PL excitation spectra before and after X-ray irradiation}

The PL spectra of the Ag-doped PGs before the irradiation are shown in Fig. 1. The excitation wavelength was $210 \mathrm{~nm}$. All the samples have emission bands at around $300 \mathrm{~nm}$. These bands are

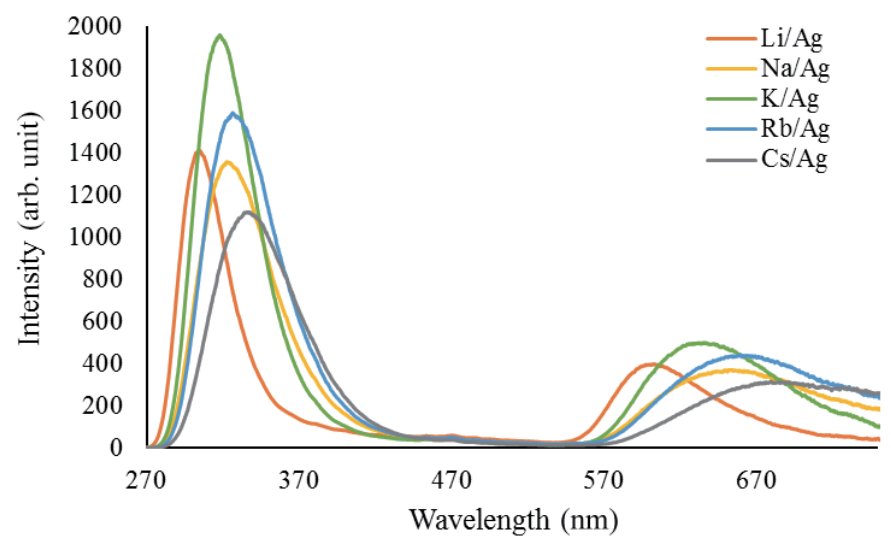

Fig. 1. (Color online) PL spectra of Ag-doped phosphate glasses of different glass compositions with excitation at $210 \mathrm{~nm}$. 
attributed to $\mathrm{Ag}^{+} .{ }^{(9)}$ Figure 2 shows the excitation spectra of the Ag-doped PGs emitted before the irradiation. The emission wavelength was set at $300 \mathrm{~nm}$. All the samples have excitation bands at around $220 \mathrm{~nm}$. The peak wavelengths and energies of the PL and excitation bands before the irradiation are summarized in Table 1. The emission band shifts toward longer wavelength, increasing the atomic number of the alkali metal in the host. On the other hand, no such correlation was found for the excitation band. The PL spectra of the Ag-doped PGs before and after the X-ray irradiation are shown in Fig. 3. The excitation wavelengths were set at the maxima of the excitation band, in the wavelength region of 280-320 nm. Figure 4 shows the excitation spectra of the RPL band of Ag-doped PGs of different glass compositions. None of the nonirradiated samples have emission bands between 400 and $750 \mathrm{~nm}$. All the irradiated samples exhibited new emission bands, i.e., RPL bands. The changes in the fluorescence spectra of all the samples after the X-ray irradiation can be explained by the changes in the valence state of Ag. It is known that RPL in commercial glass is based on the change of $\mathrm{Ag}^{+}$ions into $\mathrm{Ag}^{0}$ and $\mathrm{Ag}^{2+}$ after irradiation. ${ }^{(4)}$ This result suggests that a similar change occurs in the valence state of $\mathrm{Ag}$ in all the samples. These new emission bands are located at longer wavelengths with increasing atomic number of the alkali metal in the host. Two fluorescence bands appear to be located at 540 and $650 \mathrm{~nm}$. K/Ag is likely to have both peaks. These new excitation bands are located at longer wavelengths with increasing atomic number of the alkali metals. The peak wavelengths and energies of the RPL and the excitation bands are listed in Table 2 .

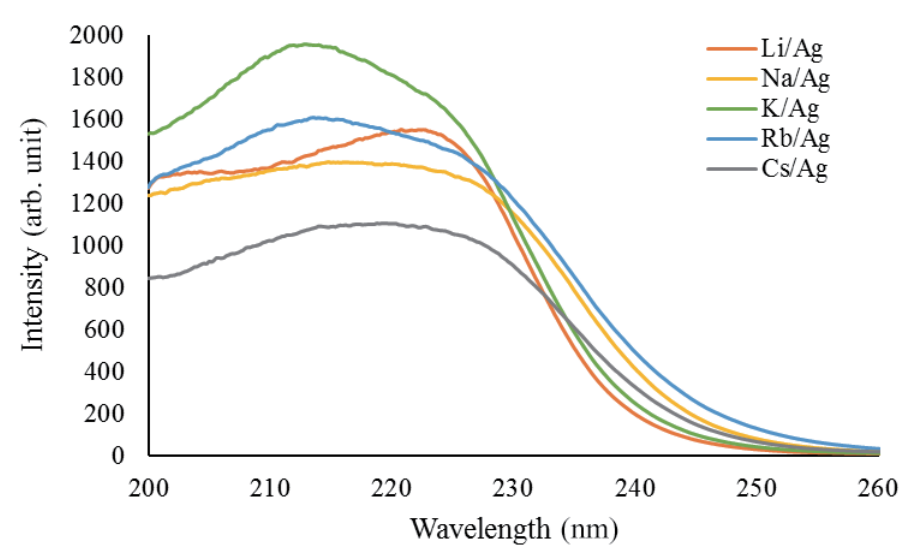

Fig. 2. (Color online) Excitation spectra of Ag-doped phosphate glasses of different glass compositions with emission at about $300 \mathrm{~nm}$.

Table 1

Peak wavelengths and energies of PL and excitation bands before irradiation.

\begin{tabular}{lccccc}
\hline & $\mathrm{Li} / \mathrm{Ag}$ & $\mathrm{Na} / \mathrm{Ag}$ & $\mathrm{K} / \mathrm{Ag}$ & $\mathrm{Rb} / \mathrm{Ag}$ & $\mathrm{Cs} / \mathrm{Ag}$ \\
\hline PL $(\mathrm{nm})$ & 304 & 323 & 318 & 327 & 338 \\
PL $(\mathrm{eV})$ & 4.08 & 3.84 & 3.90 & 3.79 & 3.67 \\
Excitation $(\mathrm{nm})$ & 223 & 215 & 213 & 214 & 220 \\
Excitation $(\mathrm{eV})$ & 5.56 & 5.77 & 5.82 & 5.79 & 5.64 \\
\hline
\end{tabular}


(a)

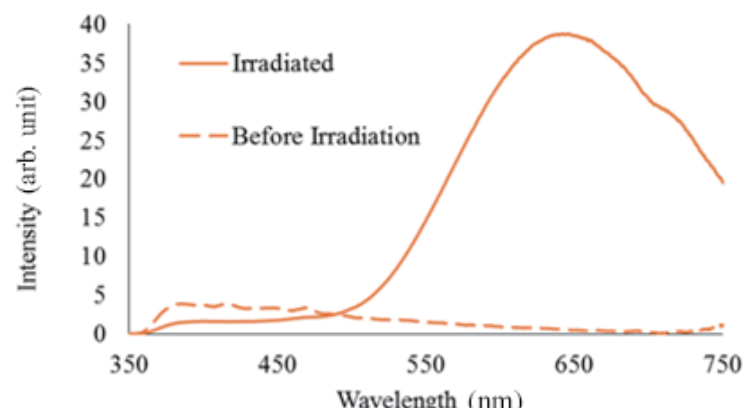

(c)

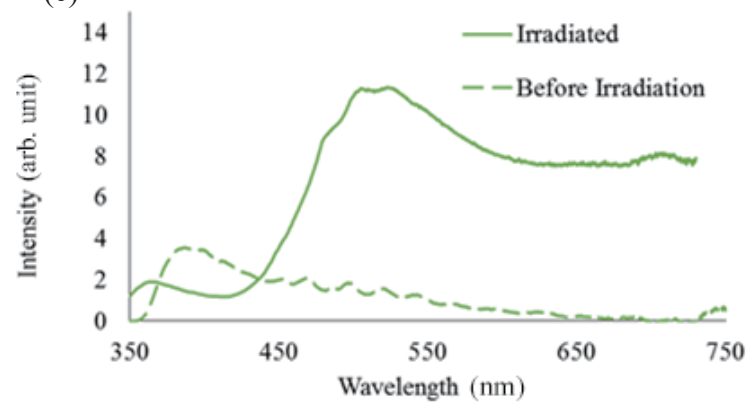

(e)

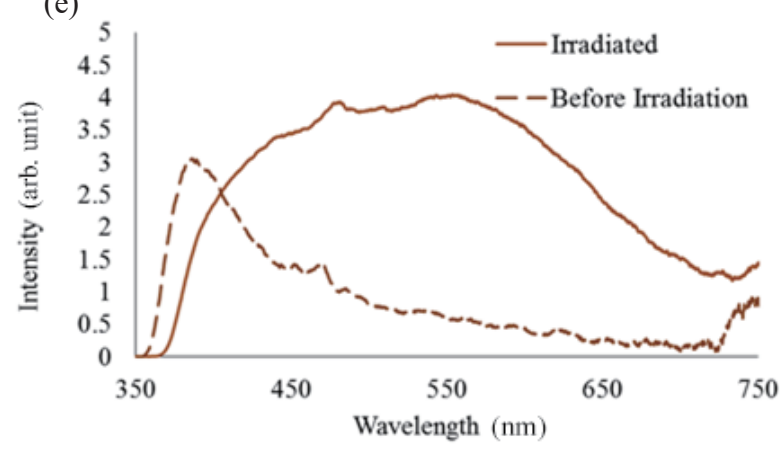

(b)

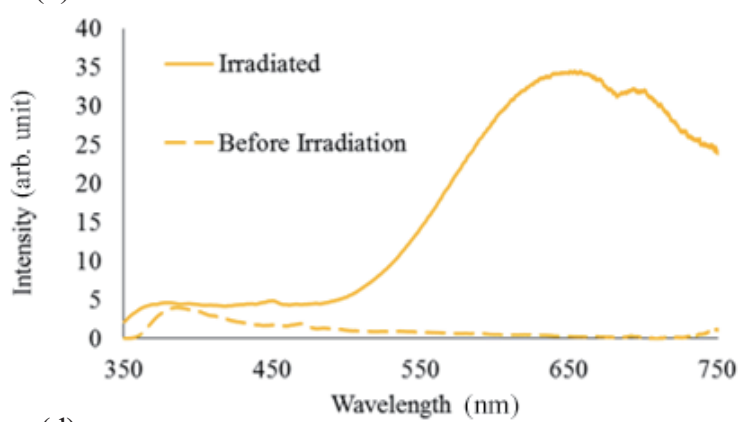

(d)

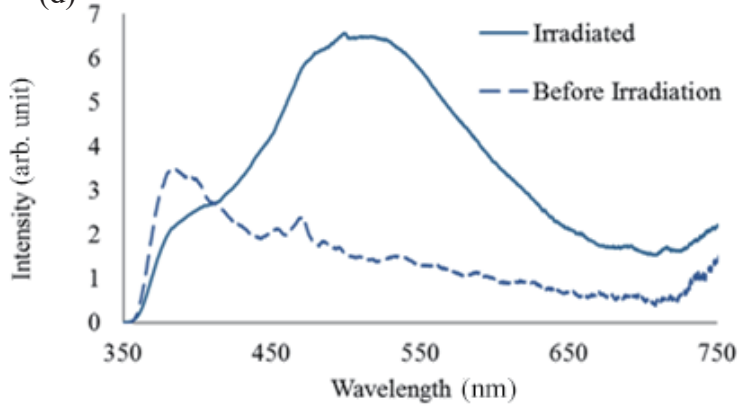

Fig. 3. (Color online) Fluorescence spectra of phosphate glasses of different glass compositions before and after the X-ray irradiation. The compositions are (a) $\mathrm{LiPO}_{3}$, (b) $\mathrm{NaPO}_{3}$, (c) $\left(\mathrm{KPO}_{3}\right)_{n}$, (d) $\mathrm{RbH}_{2} \mathrm{PO}_{4}$, and (e) $\mathrm{CsH}_{2} \mathrm{PO}_{4}$.

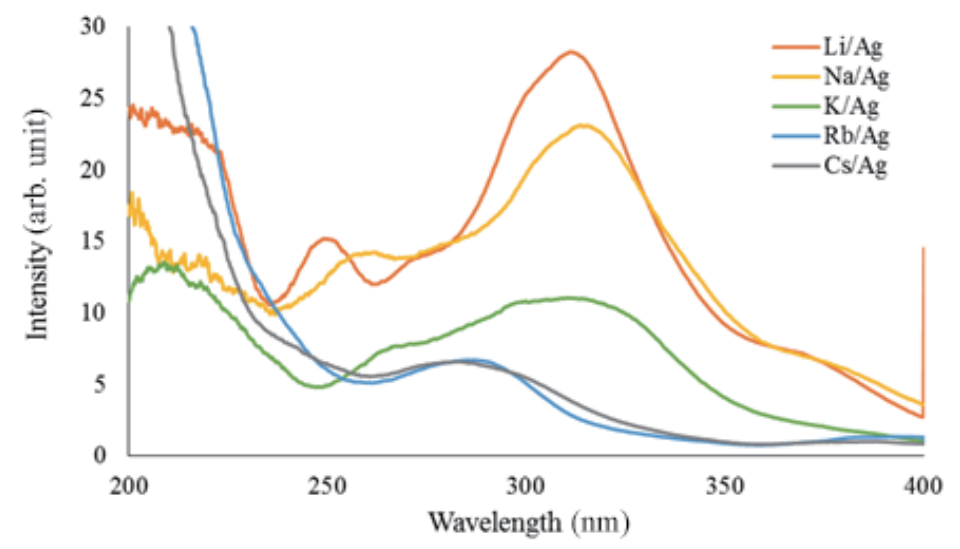

Fig. 4. (Color online) Excitation spectra of Ag-doped phosphate glasses of different glass compositions for RPL. 
Table 2

Peak wavelengths and energies of PL and excitation bands after irradiation.

\begin{tabular}{lccccc}
\hline & $\mathrm{Li} / \mathrm{Ag}$ & $\mathrm{Na} / \mathrm{Ag}$ & $\mathrm{K} / \mathrm{Ag}$ & $\mathrm{Rb} / \mathrm{Ag}$ & $\mathrm{Cs} / \mathrm{Ag}$ \\
\hline PL $(\mathrm{nm})$ & 640 & 660 & 538 & 527 & 543 \\
PL $(\mathrm{eV})$ & 1.94 & 1.88 & 2.30 & 2.35 & 2.28 \\
Excitation (nm) & 313 & 315 & 314 & 287 & 289 \\
Excitation $(\mathrm{eV})$ & 3.96 & 3.94 & 3.95 & 4.32 & 4.29 \\
\hline
\end{tabular}

\subsection{Effects of heat treatment}

Figure 5 shows the PL spectra of the X-ray irradiated Ag-doped PGs before and after heat treatments with excitation at $310 \mathrm{~nm}$. The heat treatment was carried out for $30 \mathrm{~min}$ at each temperature. As shown in Fig. 3, RPL bands were observed at $650 \mathrm{~nm}$ for $\mathrm{Li} / \mathrm{Ag}$ and $\mathrm{Na} / \mathrm{Ag}$. We observed the decrease in the RPL intensity with temperature and the disappearance of the RPL after heat treatment at $523 \mathrm{~K}$ for $30 \mathrm{~min}$ for both $\mathrm{Li} / \mathrm{Ag}$ and $\mathrm{Na} / \mathrm{Ag}$ samples. On the other hand, the RPL intensity of the Na/Ag samples increased after heat treatment at $373 \mathrm{~K}$ for $30 \mathrm{~min}$. At higher temperature, the intensity decreased. For the K/Ag sample, a peculiar feature was observed. After heat treatment at $373 \mathrm{~K}$ for $30 \mathrm{~min}$, the $\mathrm{K} / \mathrm{Ag}$ sample exhibited an emission band at $740 \mathrm{~nm}$, whereas it exhibited an emission band at $530 \mathrm{~nm}$ before the heat treatment. This result indicates that the emission band at $740 \mathrm{~nm}$ arises from changes in the sample caused by the heat treatment at $373 \mathrm{~K}$. This new band disappeared after heat treatment at $523 \mathrm{~K}$ for $30 \mathrm{~min}$. For $\mathrm{Rb} / \mathrm{Ag}$ and $\mathrm{Cs} / \mathrm{Ag}$ samples, RPL intensity increased after heat treatment at $373 \mathrm{~K}$ for $30 \mathrm{~min}$. At higher temperature, the intensity decreased, and the RPL disappeared after heat treatment at 523 and $473 \mathrm{~K}$ for $30 \mathrm{~min}$ for $\mathrm{Rb} / \mathrm{Ag}$ and $\mathrm{Cs} / \mathrm{Ag}$ samples, respectively.

All the samples were initialized by heat treatment, and this result is in line with those for commercial products. ${ }^{(10,11)}$ These results indicate that the formation and initialization processes of the fluorescent centers depend on the species of the alkali metals in the host.

\subsection{Absorption spectra before and after X-ray irradiation}

Figure 6 shows the absorption spectra of the Ag-doped PGs before and after the X-ray irradiation. We observed absorption bands at $250-300 \mathrm{~nm}$ in all the samples. Moreover, we observed new absorption bands at 300-450 nm after the X-ray irradiation, except in the Cs/Ag sample. A deconvolution with Gaussian bands leads to absorption bands at $270-350 \mathrm{~nm}$. The peak wavelengths of these absorption bands are consistent with those of the excitation bands shown in Fig. 4. Therefore, these new absorption bands are correlated with the appearance of the RPL. On the other hand, we observed little change for the $\mathrm{Cs} / \mathrm{Ag}$ sample. This result is consistent with the excitation spectrum in Fig. 4, which has no excitation band around 300-400 $\mathrm{nm}$ at room temperature.

\subsection{Decay characteristics of RPL fluorescence}

Figure 7 shows the fluorescence decay curves of Ag-doped PGs of Li/Ag with excitation at 325 $\mathrm{nm}$. The measurements were also performed for the other samples. The monitored wavelengths were $640,660,540,530$, and $540 \mathrm{~nm}$ for $\mathrm{Li} / \mathrm{Ag}, \mathrm{Na} / \mathrm{Ag}, \mathrm{K} / \mathrm{Ag}, \mathrm{Rb} / \mathrm{Ag}$, and $\mathrm{Cs} / \mathrm{Ag}$, respectively. 
(a)

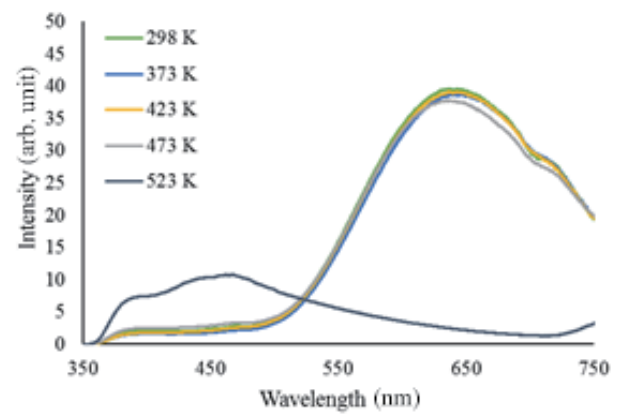

(b)

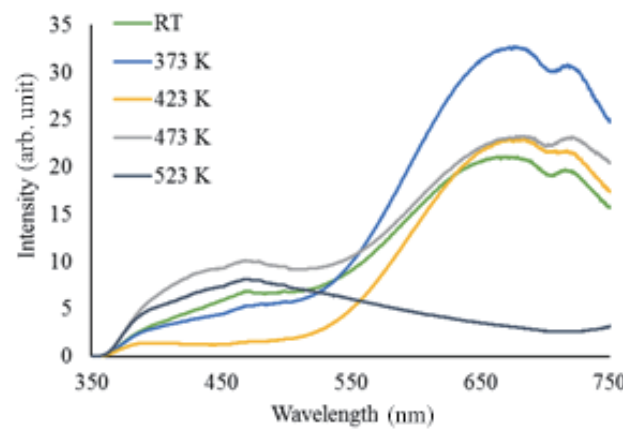

(c)

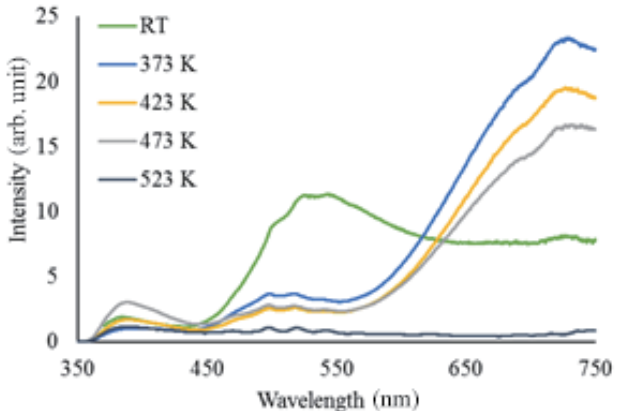

(d)

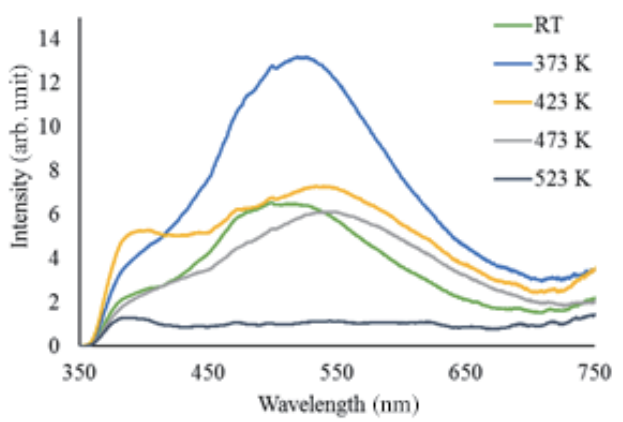

(e)

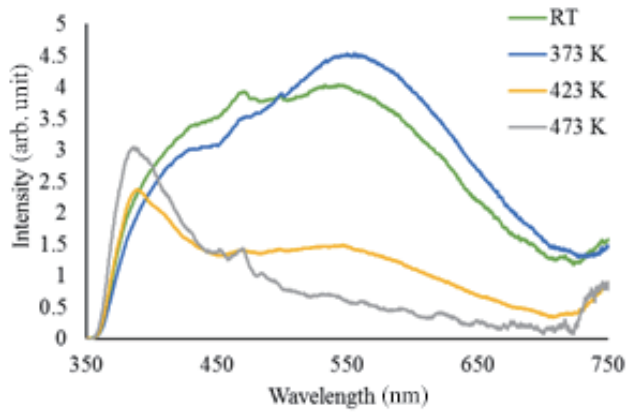

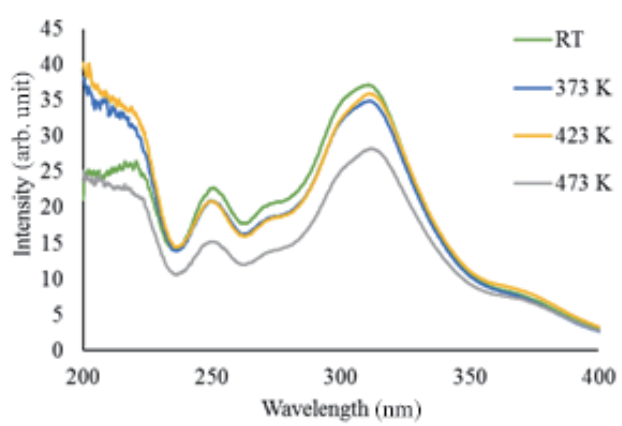
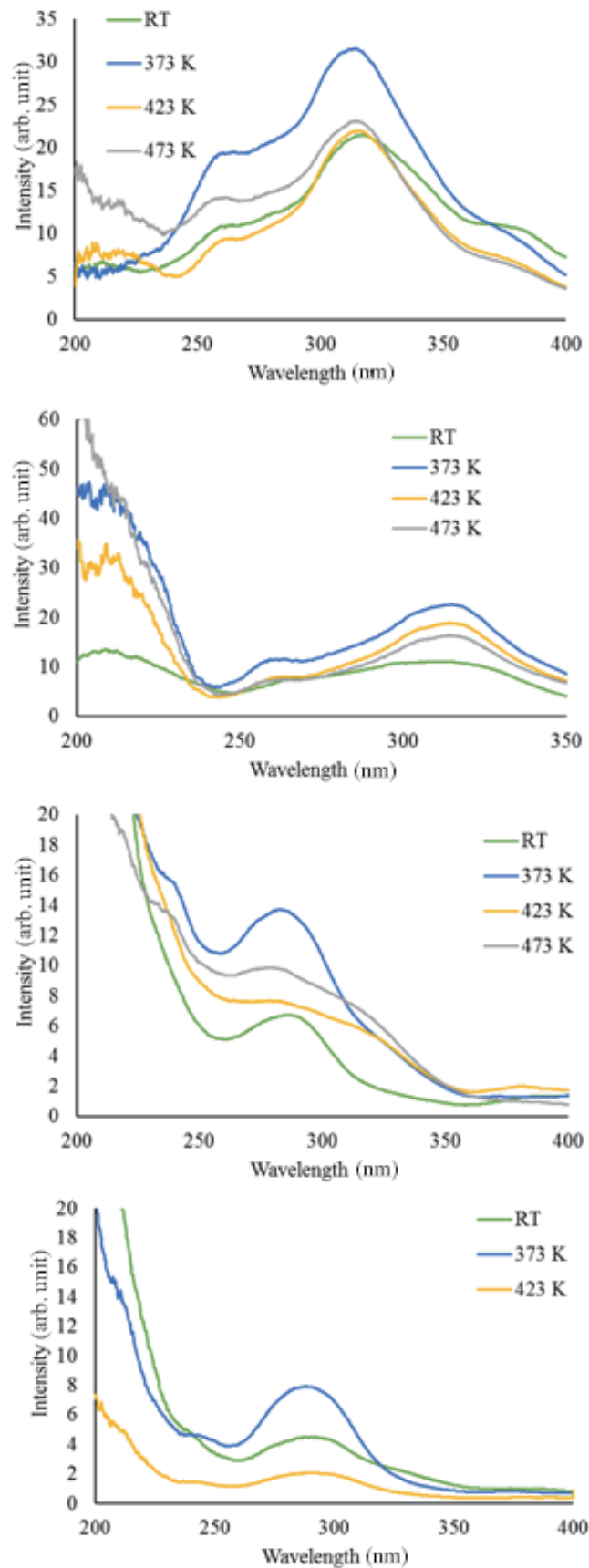

Fig. 5. (Color online) Fluorescence spectra (left) and excitation spectra (right) of Ag-doped phosphate glasses of different glass compositions for RPL. The compositions are (a) Li/Ag, (b) Na/Ag, (c) K/Ag, (d) Rb/Ag, and (e) $\mathrm{Cs} / \mathrm{Ag}$. 

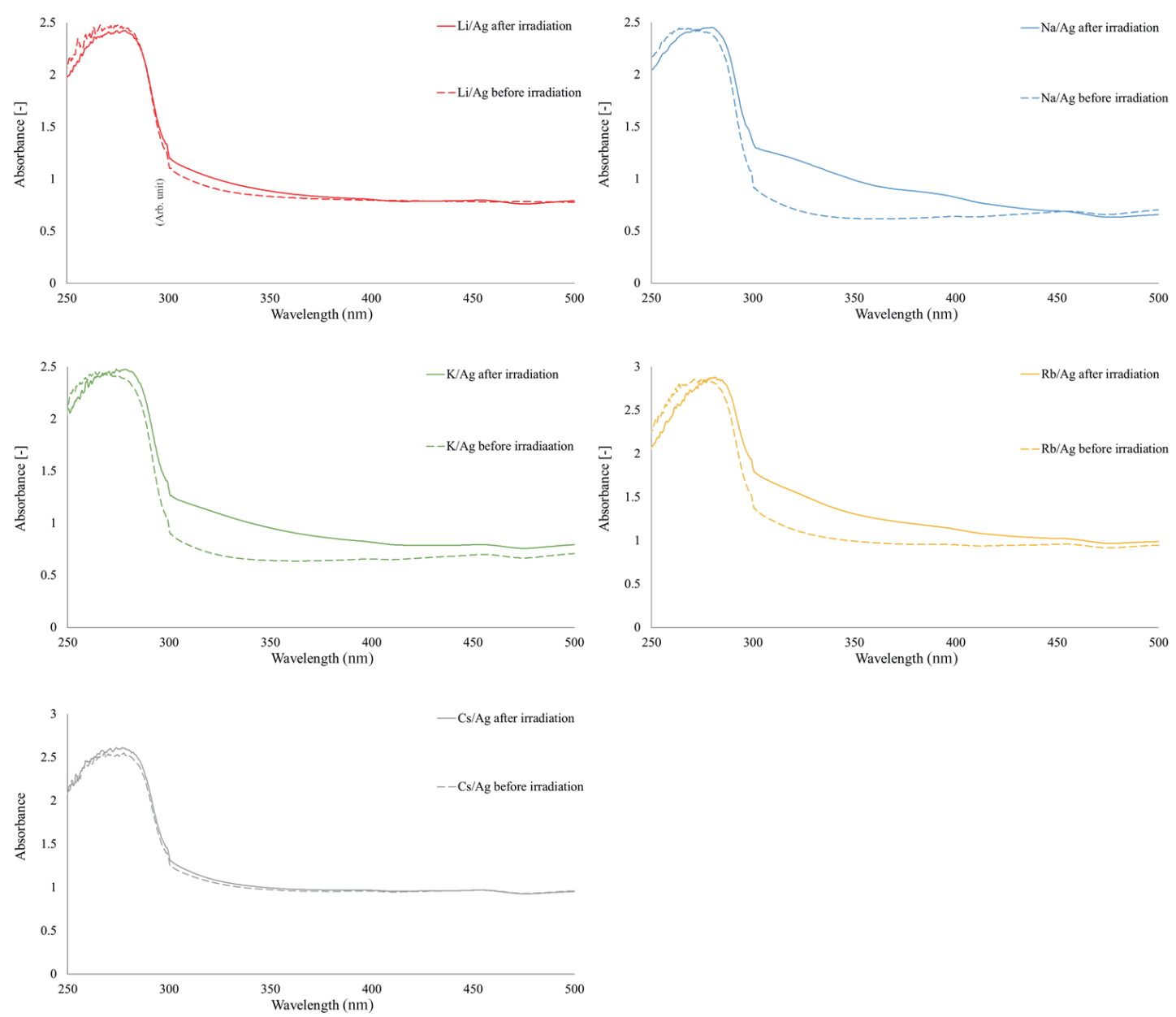

Fig. 6. (Color online) Absorption spectra of Ag-doped phosphate glasses of different glass compositions before and after X-ray irradiation.

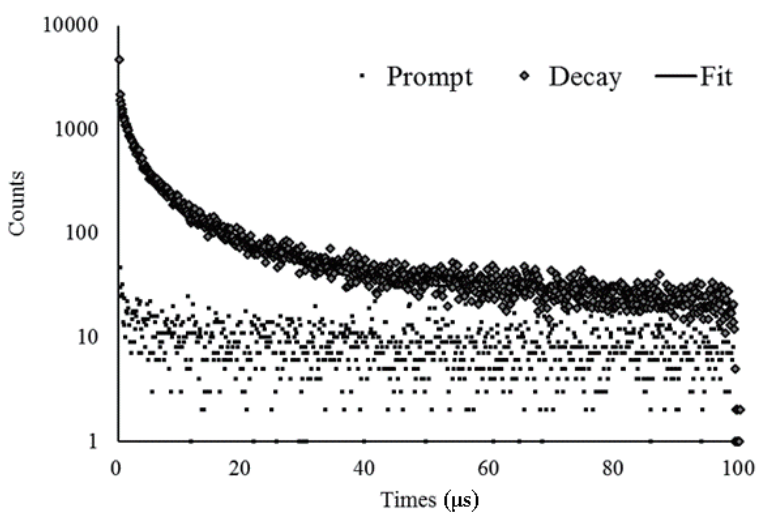

Fig. 7. Fluorescence decay curve of $\mathrm{Li} / \mathrm{Ag}$ with excitation at $325 \mathrm{~nm}$. The detection wavelength was $640 \mathrm{~nm}$. 
Table 3

Decay time constants of RPL fluorescence.

\begin{tabular}{lccccc}
\hline & $\mathrm{Li} / \mathrm{Ag}$ & $\mathrm{Na} / \mathrm{Ag}$ & $\mathrm{K} / \mathrm{Ag}$ & $\mathrm{Rb} / \mathrm{Ag}$ & $\mathrm{Cs} / \mathrm{Ag}$ \\
\hline $\mathrm{T}_{1}(\mu \mathrm{s})$ & 1.23 & 1.17 & 1.13 & 0.95 & 0.19 \\
$\mathrm{~T}_{2}(\mu \mathrm{s})$ & 9.46 & 7.90 & 15.3 & 14.6 & 8.55 \\
\hline
\end{tabular}

The decay curves were satisfactorily fitted with a sum of two exponential decay functions. Table 3 shows the list of the decay time constants. These decay time constants became shorter with increasing atomic number of the alkali metals.

\section{Conclusions}

We investigated the PL and RPL properties of Ag-doped phosphate glasses of various compositions in a host. We focused on the alkali metal species as cations in the host. The RPL properties, such as the peak wavelengths of the RPL bands and the thermal stability of the new fluorescent centers, strongly depend on the alkali metal species in the host. These results indicate that RPL fluorescent center formation and initialization processes depend on the alkali metal species in the host phosphate glasses.

\section{Acknowledgements}

The authors wish to thank Mr. S. Kayamori for his assistance in carrying out experiments. This work was partly supported by the Technical Division, Graduate School of Engineering, Tohoku University and the Cooperative Research Project of the Research Institute of Electronics, Shizuoka University.

\section{References}

1 J. H. Schulman and W. D. Compton: Color Centers in Solids (Pergamon Press, Inc., New York, 1963) p. 160.

2 R. Yokota: Oyo Buturi 38 (1969) 1077 (in Japanese).

3 R. Yokota: Oyo Buturi 40 (1971) 1292 (in Japanese).

4 Y. Miyamoto, Y. Takei, H. Nanto, T. Kurobori, A. Konnai, T. Yanagida, A. Yoshikawa, Y. Shimotsuma, M. Sakakura, K. Miura, K. Hirao, Y. Nagashima, and T. Yamamoto: Radiat. Meas. 46 (2011) 1480.

5 Y. Miyamoto, T. Yamamoto, K. Kinoshita, S. Koyama, Y. Takei, H. Nanto, Y. Shimotsuma, M. Sakakura, K. Miura, and K. Hirao: Radiat. Meas. 45 (2010) 546.

6 G. Okada, B. Morrell, C. Koughia, A. Edgar, C. Varoy, G. Belev, T. Wysokinski, D. Chapman, and S. Kasap: Appl. Phys. Lett. 99 (2011) 121105.

7 A. V. Dmitryuk, S. E. Paramzina, A. S. Perminov, N. D. Solov'eva, and N. T. Timofeev: J. Non-Cryst. Solids 202 (1996) 173.

8 H. Tatsumi, G. Okada, T. Yanagida, and H. Masai: Chem. Lett. (2016) (in press). doi:10.1246/cl.151078

9 W. Zheng and T. Kurobori: Nucl. Instrum. Methods Phys. Res., Sect. B 269 (2011) 2814.

10 Y. Miyamoto, H. Nanto, T. Kurobori, Y. Fujimoto, T. Yanagida, J. Ueda, S. Tanabe, and T. Yamamoto: Radiat. Meas. 71 (2014) 529.

11 T. Nomura, T. Ikegami, and N. Juto: Radioisotopes 51 (2002) 85 (in Japanese). 